\title{
Breakeven Analysis of Energy Storage Systems in PJM Energy Markets
}

\section{Citation}

Mauricio B.C. Salles, Taina N. Gadotti, Michael J. Aziz, \& William W. Hogen. 2017. Breakeven Analysis of Energy Storage Systems in PJM Energy Markets. 6th International Conference on Renewable Energy Research and Application, San Diego CA Nov 5-8 2017.

\section{Published Version}

10.1109/ICRERA.2017.8191092

\section{Permanent link}

http://nrs.harvard.edu/urn-3:HUL.InstRepos:42595160

\section{Terms of Use}

This article was downloaded from Harvard University's DASH repository, and is made available under the terms and conditions applicable to Other Posted Material, as set forth at http:// nrs.harvard.edu/urn-3:HUL.InstRepos:dash.current.terms-of-use\#LAA

\section{Share Your Story}

The Harvard community has made this article openly available.

Please share how this access benefits you. Submit a story.

Accessibility 


\section{Breakeven Analysis of Energy Storage Systems in PJM Energy Markets}

\author{
Maurício B. C. Salles ${ }^{1}$ and Taina N. Gadotti ${ }^{1}$ \\ ${ }^{1}$ Laboratory of Advanced Electric Grids - LGrid, \\ Polytechnic School, University of São Paulo - USP, \\ São Paulo, Brazil \\ mausalles@usp.br, taina.gadotti@usp.br
}

\author{
Michael J. Aziz ${ }^{2}$ and William W. Hogan ${ }^{3}$ \\ ${ }^{2}$ John A. Paulson School of Engineering and Applied Sciences \\ ${ }^{3}$ John F. Kennedy School of Government \\ Harvard University \\ Cambridge, USA \\ maziz@harvard.edu, william_hogan@harvard.edu
}

\begin{abstract}
Energy arbitrage is attracting interest of Energy Storage Systems developers and owners to provide net revenue in transmission and distribution systems. We have analyzed the potential revenue of a generic Energy Storage System (ESS) within the electricity market of PJM in 8 different locations where such technology is already installed. We used hourly DayAhead and Real-time locational marginal prices over the sevenyear period 2008-2014, assuming a price-taking dispatch with perfect foresight. The charge-discharge profiles were optimized to determine the minimum potential revenue for $1 \mathrm{MW}$ system for $70 \%$ round trip efficiency in those 8 locations. We performed a sensitivity analysis to verify the dependence on rated discharge duration and its variation over the years. We determined the breakeven overnight installed cost below which energy arbitrage would be profitable.
\end{abstract}

Keywords - battery; electricity market; energy arbitrage; energy storage; real-time market.

\section{INTRODUCTION}

The adoption of massive energy storage systems (ESS) can be a game changer for the grid; however, technological and financial challenges must be overcome. There are many possibilities to use ESS to benefit the grid operation and the costumers in terms of reliability, cost of energy, power quality, cutting emissions and flexibility [1]. New York State is moving to meet $50 \%$ renewable energy by 2030 and the replacement of old peaking plants with ESS could be a cost-effective option to reduce emissions [2]. California is also going in this direction to accommodate targets on renewable energies. The resiliency against natural disaster, man-made attacks and extreme events is a concern that the operators and the consumers will have to deal with at increasing rates because of climate change [3],[4]; this will also accelerate the integration of ESS.

The existing and officially announced electrochemical ESS over $1 \mathrm{MW}$ of rated power in the United States [5] are shown in Fig. 1. The most installed electrochemical ESS is by far the Lithium-ion battery with 69 units; there are also five flow batteries and 11 lead-acid batteries. The discharge duration on rated capacity varies from few minutes to six hours. Most of the Lithium-ion batteries are below three hours and most flow

This work was supported by São Paulo Research Foundation (FAPESP) grants \#2014/05261-0 and \#2017/12257-7 and the U.S. Department of Energy Advanced Research Projects Agency_Energy award no. DE-AR0000348. batteries are over three hours. A discharge duration around 10 hours can increase the revenue during spikes of electricity prices in energy arbitrage [6]; however long discharge duration is unimportant for regulation markets.

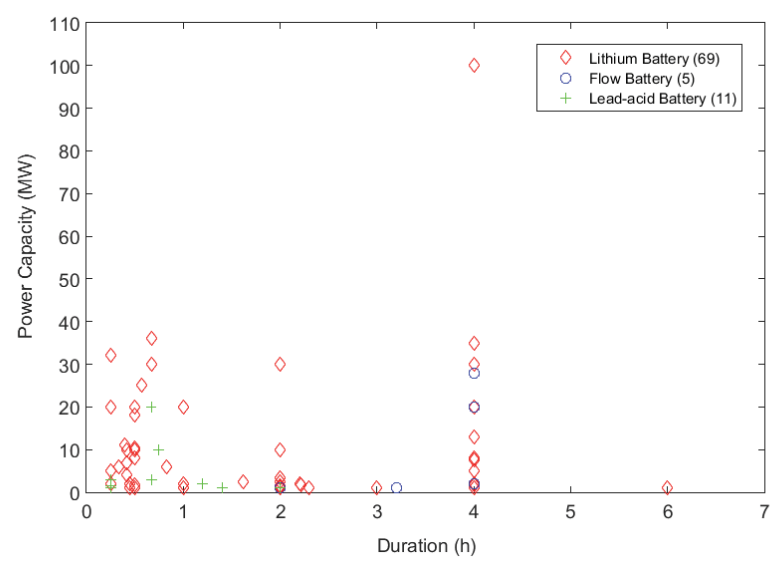

Fig. 1. Electrochemical energy storage systems (ESS) installations over $1 \mathrm{MW}$ in the United States (September 2017), based on the data provided in [5].

The PJM Interconnection is one of the most successful markets for ESS and has inspired other markets even outside the United States [7]. However, at the beginning of 2017, PJM put in place new rules for the frequency regulation market that lowered revenues from $\$ 623$ in 2014 to $\$ 86$ today for a 20megawatt/5-megawatt-hour ESS [8]. In part, this change reflects the small scale of the regulation market. By contrast, the potential scale of energy arbitrage is larger.

In section II, the selection of the nodes and the electricity price from 2008 to 2014 in PJM are discussed. Section III shows the potential arbitrage revenue of ESS for a minimum scenario of forcast in PJM wholesale markets. Section IV presents a breakeven overnight install cost for various hours of storage. The main conclusions are presented in section IV.

\section{Selection of Location With ESS In PJM}

We have chosen to analyze eight locations with ESS units over $10 \mathrm{MW}$ with full electricity price data from 2008 to 2014. 


\section{A. Node Characteristics}

TABLE I shows the selected nodes in PJM. We also included a node with high potential revenue but with only $2 \mathrm{MW}$ of installed ESS for comparison (Hagerstown).

TABLE I. SELECTED NODES WITH ESS IN OPERATION.

\begin{tabular}{|c|c|c|c|}
\hline \multirow{2}{*}{ Node ID } & \multicolumn{3}{|c|}{ Location } \\
\cline { 2 - 4 } & City & State & Zip Code \\
\hline 2585 & Hagerstown & Maryland & 21740 \\
\hline 1505 & Blairstown & New Jersey & 7825 \\
\hline 3434 & DeKalb & Georgia & 60112 \\
\hline 2971 & McHenry County & Illinois & 60102 \\
\hline 3123 & Joliet & Illinois & 60431 \\
\hline 6454 & Moraine & Ohio & 45439 \\
\hline 712 & Mead Township & Pennsylvania & 16313 \\
\hline 2196 & Cumberland & Maryland & 21502 \\
\hline 660 & Somerset County & Pennsylvania & 15411 \\
\hline
\end{tabular}

The ESS installed in these nodes are in operation and its main characteristics are presented in TABLE II. Only three of the nine ESS first service energy arbitrage whereas four of them first service frequency regulation, and two first service capacity.

TABLE II. MAIN CHARACTERISTIC OF THE ESS IN OPERATION AT SELECTED NODES IN PJM.

\begin{tabular}{|c|c|c|c|}
\hline \multirow[b]{2}{*}{ Node ID } & \multicolumn{3}{|c|}{ Existing Energy Storage in Operation } \\
\hline & Technology & $\begin{array}{c}\text { Rated } \\
\text { Power }(k W)\end{array}$ & First Service \\
\hline 2585 & Lithium-ion Battery & 2000 & $\begin{array}{c}\text { Electric Energy } \\
\text { Time Shift } \\
\text { (arbitrage) }\end{array}$ \\
\hline 1505 & $\begin{array}{l}\text { Open-loop Pumped } \\
\text { Hydro Storage }\end{array}$ & 400000 & $\begin{array}{c}\text { Electric Energy } \\
\text { Time Shift } \\
\text { (arbitrage) }\end{array}$ \\
\hline 3434 & Lithium-ion Battery & 20000 & $\begin{array}{l}\text { Frequency } \\
\text { Regulation }\end{array}$ \\
\hline 2971 & Lithium-ion Battery & 19800 & $\begin{array}{c}\text { Electric Supply } \\
\text { Capacity }\end{array}$ \\
\hline 3123 & Lithium-ion Battery & 19800 & $\begin{array}{l}\text { Frequency } \\
\text { Regulation }\end{array}$ \\
\hline 6454 & Lithium-ion Battery & 20000 & $\begin{array}{l}\text { Frequency } \\
\text { Regulation }\end{array}$ \\
\hline 712 & $\begin{array}{l}\text { Open-loop Pumped } \\
\text { Hydro Storage }\end{array}$ & 440000 & $\begin{array}{l}\text { Electric Energy } \\
\text { Time Shift } \\
\text { (arbitrage) }\end{array}$ \\
\hline 2196 & Lithium-ion Battery & 10000 & $\begin{array}{c}\text { Electric Supply } \\
\text { Reserve } \\
\text { Capacity } \\
\end{array}$ \\
\hline 660 & Lithium-ion Battery & 10400 & $\begin{array}{l}\text { Frequency } \\
\text { Regulation }\end{array}$ \\
\hline
\end{tabular}

\section{B. Real-time market (RTM)}

The Real-time market (RTM) is a physical market with a 5minute interval price. Both Day-ahead market (DAM) and RTM settlements are performed on hourly-based Locational Marginal Price (LMP), but the RTM is based on actual system condition deviations from the Day-ahead schedule [9]. Fig. 2 shows the RTM average LMP in PJM from 2008 to 2014, for the Node ID 1505, in Blairstown, New Jersey. We can see that the average in 2008 were the highest.

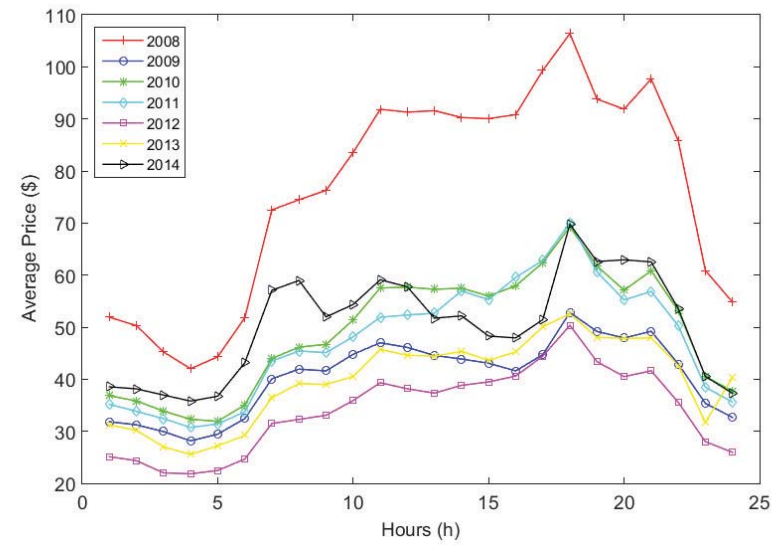

Fig. 2. RTM hourly-based average LMP price in PJM from 2008 to 2014 in Blairstown, New Jersey.

Fig. 3 shows that very high spikes of LMP happened in 2014 that could be reflected in high potential revenues for an ESS in the first three months of the year.

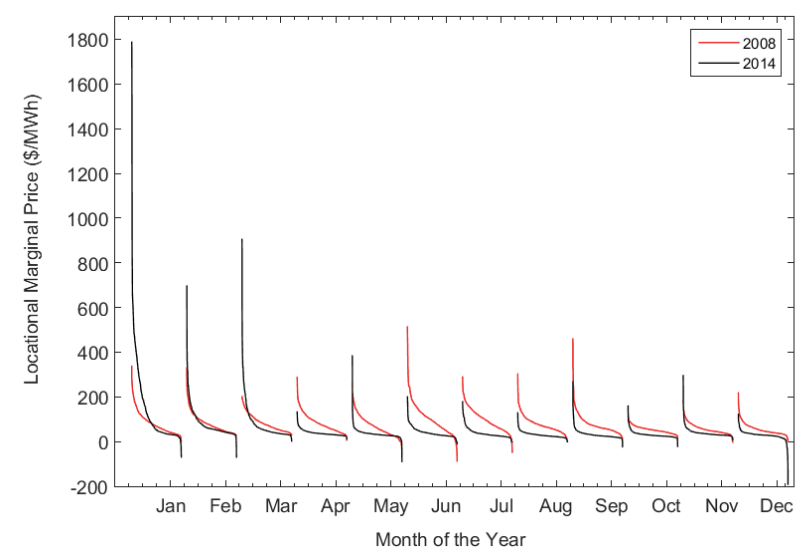

Fig. 3. Classified RTM hourly-based LMP per month in PJM in 2008 and 2014 in Blairstown, New Jersey.

\section{Potential Arbitrage Revenue in Seleceted Nodes}

This section covers the evaluation of the potential arbitrage revenue using a generic storage model. The maximum revenue that an ESS can obtain in the RTM is based on a price-taking model with perfect forecast method. This calculation implies that the future price is already known or historical data can be used. We shown in [10] that the use of the DAM prices settlement could be used as a forecast for the dispatch in RTM to achieve more revenue than is available in DAM. Using this 
approach, the ESS owner can capture between $70 \%$ and $85 \%$ of the available revenue in the RTM.

\section{A. The methodology}

A generic linear optimization model of price-taking ESS considering perfect forecast for hourly-based price data were adopted, as presented in [6],[10],[11]. A round trip efficiency of $70 \%$ was chosen to represent the efficiency of a Flow Battery and it can be fully discharged [12]. The charge and the discharge rated power is $1 \mathrm{MW}$ for all analyses. The pricetaking model assumes that the individual ESS has no impact on the settlement price. Equation (1) represents the implemented model:

$$
\begin{aligned}
& \underset{c, d, s}{\operatorname{Max}} \sum_{t=1}^{T} p_{t}\left(d_{t}-c_{t}\right) \\
& s_{t}=s_{t-1}+\eta c_{t}-d_{t} \\
& d_{t}, c_{t} \in[0, \kappa] \\
& s_{t} \in[0, h \kappa]
\end{aligned}
$$

where

$T$ : number of hours in dispatch horizon;

$p_{t}$ : energy price in hour $\mathrm{t}$;

$\kappa$ : power capacity of storage device;

$h$ : number of hours of discharge at rated power;

$d_{t}$ : discharge power in hour $\mathrm{t}$ of storage device;

$c_{t}$ : charge power in hour $t$ of storage device;

$s_{t}$ : state of charge in hour $t$ of storage device;

$\eta$ : round trip efficiency of storage device.

This model provides preliminary estimates of the net revenues that would be captured through price arbitrage. The optimal solution always had charging and discharging at either zero or the maximum power rate, optimal solution never had both charging and discharging occurring in the same hour.

Direct current/alternating current (DC/AC) conversion efficiencies are improving, and new storage technologies (for example some Li-ion batteries, flywheels and supercapacitors) can have high efficiency around 90\% [12]. The choice of a round trip efficiency of $70 \%$ was taken to represent a flow battery. This value of round trip efficiency considers the pump based on an induction motor used to make the electrolytes circulate inside the system [12]-[14].

\section{B. Energy arbitrage revenue}

In [10], we presented a method to capture the equivalent of more than $100 \%$ of the potential revenue opportunities in the DAM. This method uses the DAM settlement price as a forecast to determine the optimized dispatch, then we use the charge and discharge schedule to participate in real-time for the known DAM prices. This approach would be feasible under the PJM market definition. The potential arbitrage revenue of an ESS were evaluated encompassing 7395 nodes of PJM using this approach for the period of 2008 to 2014.
In Fig. 4, the curves of the average revenue of the 7-year data encompassing 7395 nodes (or locations) for 4, 8 and 12 MWh of energy capacity are shown. The selected nodes presented in TABLE I are included inside the curves in its relative classified position with the other 7395 nodes. Hagerstown and Blairstown are the two best nodes for energy arbitrage from the selected nodes with an installed ESS.

The third node with a relative good potential is the Dekalb, Georgia. The other nodes do not represent a significative revenue in the period; however, it does not mean that there is no high potential revenue in specific days. As show in Fig. 3, there can be very high spikes on LMP in few hours and few days that might reflect in high revenue [6].

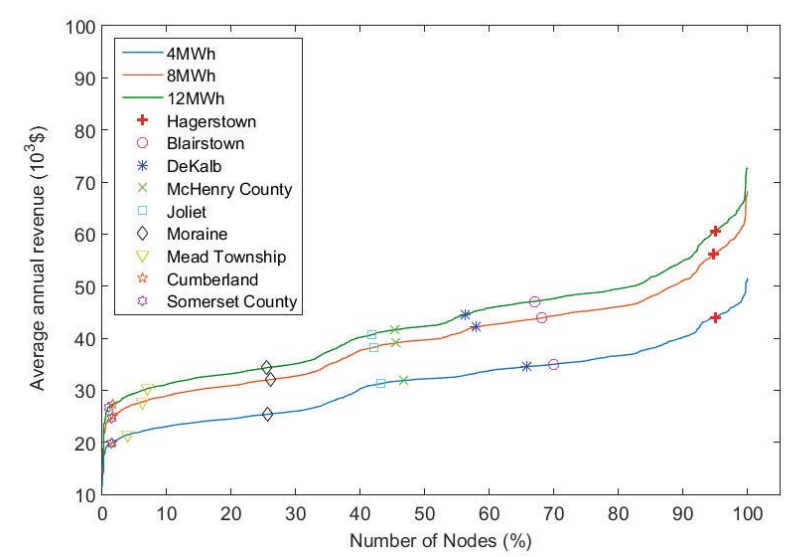

Fig. 4. The curves represent a yearly-based average potential arbitrage revenue from 2008 to 2014 of a ESS with $70 \%$ round trip efficiency and 1 MW of rated power for RTM in PJM using the DAM price settlement as forecast, encompassing 7395 nodes. The abscissa is the percentage of nodes with revenue less than the value given by the ordinate; the values are independently sorted.

In Fig. 5, the average potential revenue from 2008 to 2014 for the nine selected nodes is presented. The sensitivity to the energy/power ratio can be seen. The increment in revenue for an ESS with more than $6 \mathrm{MWh}$ gets smaller for each increment in energy capacity.

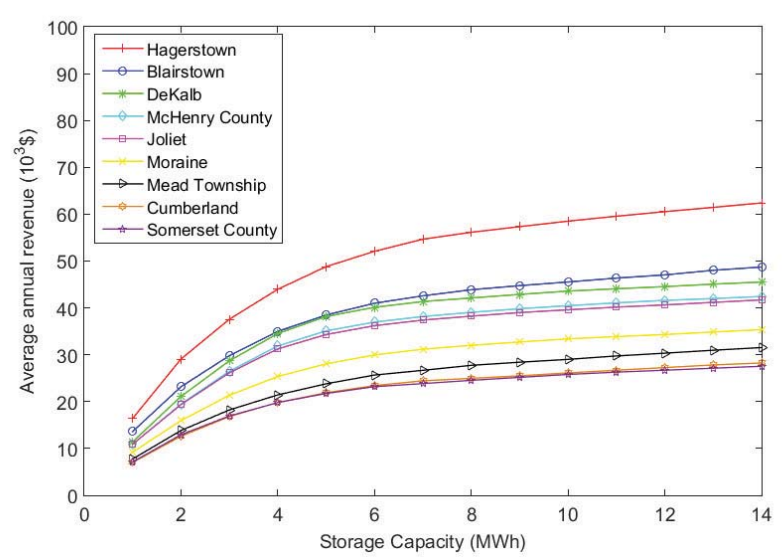

Fig. 5. The curves represent a yearly-based average potential arbitrage revenue from 2008 to 2014 of a ESS with $70 \%$ round trip efficiency and $1 \mathrm{MW}$ of rated power for RTM in PJM using the DAM prices settlement as forecast, encompassing the 9 selected nodes. The abscissa is the energy capacity, varying from 1 to $14 \mathrm{MWh}$. 
In Fig. 6 and Fig. 7, we can see the distribution per year of revenue for the node in Hagerstown and in Blairstown, respectively. The difference between 2008 and the second-best year (2014) is large. Higher prices along the year have more impact on total year revenue than very high prices in few days.

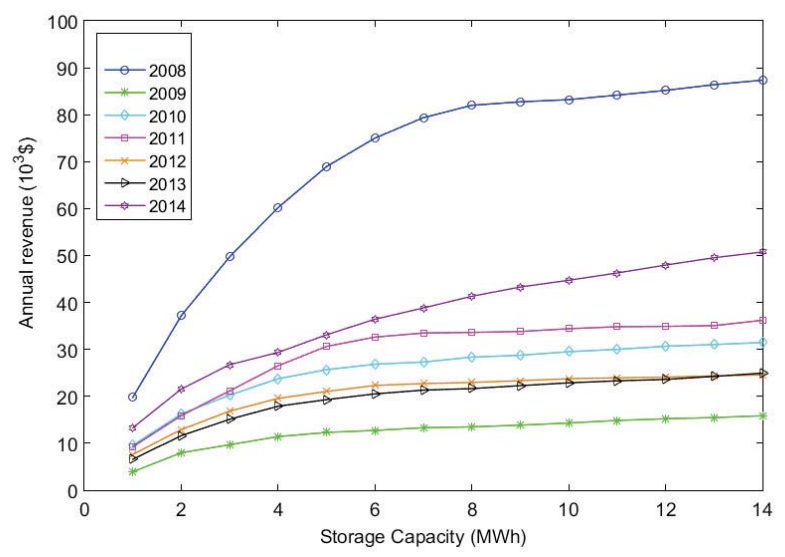

Fig. 6. The curves represent the potential arbitrage revenue in Hagerstown from 2008 to 2014 of a ESS with $70 \%$ round trip efficiency and 1 MW of rated power for RTM in PJM using the DAM prices settlement as forecast. The abscissa is the energy capacity from $1 \mathrm{MWh}$ to $14 \mathrm{MWh}$.

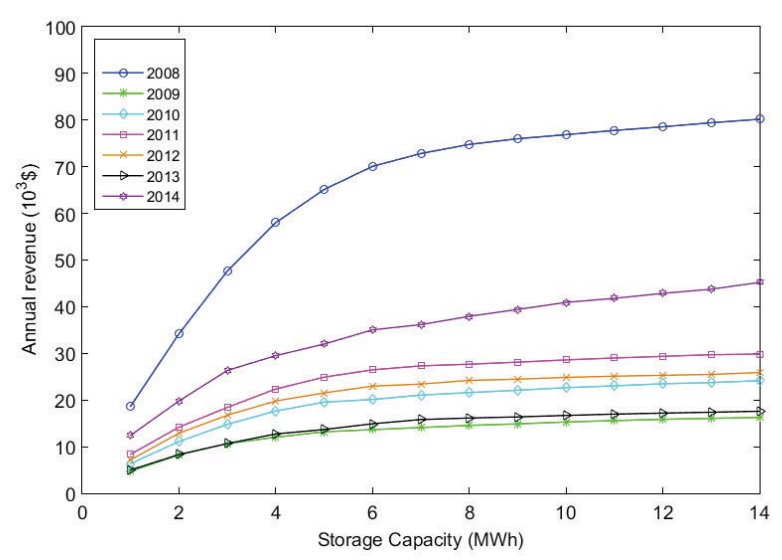

Fig. 7. The curves represent the potential arbitrage revenue in Blairstown from 2008 to 2014 of a ESS with $70 \%$ round trip efficiency and 1 MW of rated power for RTM in PJM using the DAM prices settlement as forecast. The abscissa is the energy capacity from $1 \mathrm{MWh}$ to $14 \mathrm{MWh}$.

\section{BREAKEVEN OVERNight INSTALLED Cost}

We analyzed the breakeven overnight installed cost of an ESS using the net revenue determined in section III, for the various years and energy capacity for the selected nodes. We adopted an approach independent of the ESS technology that derives the net installed costs (after taxes and depreciation) to obtain an annualized capital recovery factor (CRF) that would return the present value of the investment over the life of the project. The net revenues based on the analysis is compared with the CRF [15].

Even with an approach intendent of the ESS technology, the parameter values will differ from one technology to another. We assume 20-year life for flow batteries [16] and no special subsidies. The Net Operating Revenue Before Corporate Taxes (NR) was set equal to the PJM net revenue analysis for the various years and locations. Using this equality, the round trip losses, energy purchase costs and pricing assumptions reflects the various sensitivity cases for the net revenues.

The annual Fixed Operating and Maintenance Cost (OM) $(v)$ is assumed to be $2 \%$ of the initial capital costs for flow batteries [16]. The assumptions for tax rates and related financial parameters was based on the Annual Energy Outlook of the Energy Information Administration [17]. All quantities are in real terms except where specified:

$$
\begin{gathered}
i=\text { Nominal corporate borrowing rate }=7.1 \% \\
\tau=\text { Corporate tax rate }=38 \% \\
d=\text { Share of investment financed by debt }=45 \% \\
E=\text { Risk adjusted real return on equity }=9.3 \% \\
\pi=\text { Expected inflation rate }=2.0 \%
\end{gathered}
$$

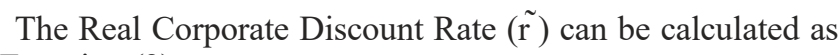
in Equation (2):

$$
\tilde{r}=d(i(1-\tau)-\pi)+(1-d) E
$$

We assume 7-year depreciation as suggested in [16]. The base case assumption for storage is no investment tax credit (ITC), i.e., $\rho_{I T C}=0 \%$. Considering the assumptions presented before $(0 \%$ ITC, a 20 -year project life and a 15 -year tax depreciation life), the Adjusted Capital Recovery Factor $(A C R F)$ is equal to $8.66 \%$, more details of the calculation can be found in [10]. Now, the net revenue analysis can be applied together with the ACRF to produces breakeven installed cost.

The cost is a linear combination of the marginal cost per unit power capacity and the marginal cost per unit energy capacity for a flow battery. We presented the overnight breakeven installed cost in $\$ / \mathrm{kWh}$ to simplify the comparison with other storage systems.

We performed the breakeven calculation for an ESS in RTM with a price forecast based on the DAM, $70 \%$ round trip efficiency, and 20-year project life for Hagerstown, Maryland (Fig. 8), Blairstown, New Jersey (Fig. 9) and DeKalb, Georgia (Fig. 10). The distribution of breakeven overnight installed costs is shown with dependence on storage capacity and year. All of Figures 8-10 indicate rapidly declining ESS breakeven $\operatorname{cost} / \mathrm{kWh}$ when the energy/power ratio increases. The returns diminish in revenue $/ \mathrm{kWh}$ but increases in absolute value. However, the actual cost of flow batteries per $\mathrm{kWh}$ drops markedly with increasing discharge duration by mainly increasing the size of the electrochemical storage tanks filled with electrolyte. For this reason, further study must be performed to determine the ideal discharge durations. The cost for a specific flow battery discharge duration might be inside the range of breakeven costs before other discharge durations.

The price evolution of energy storage systems has been dropping. However, it is still unclear when this application will become economically viable. 


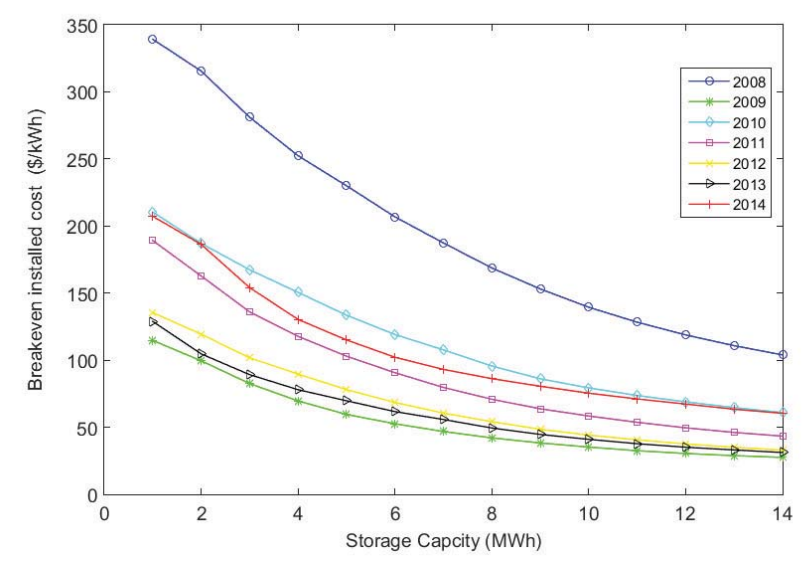

Fig. 8. Distribution of breakeven overnight installed cost for Hagerstown, Maryland in the PJM RT-Market for an ESS vs. energy capacity (1-14 MWh) for each of the years studied. Assumed round trip efficiency is $70 \%$ and project lifetime is 20 years.

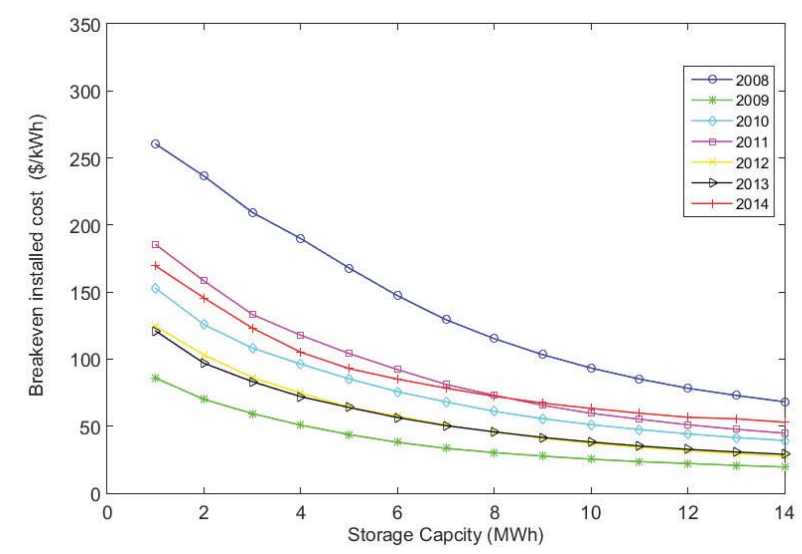

Fig. 9. Distribution of breakeven overnight installed cost for Blairstown, New Jersey in the PJM RT-Market for an ESS vs. energy capacity (1-14 MWh) for each of the years studied. Assumed round trip efficiency is $70 \%$ and project lifetime is 20 years.

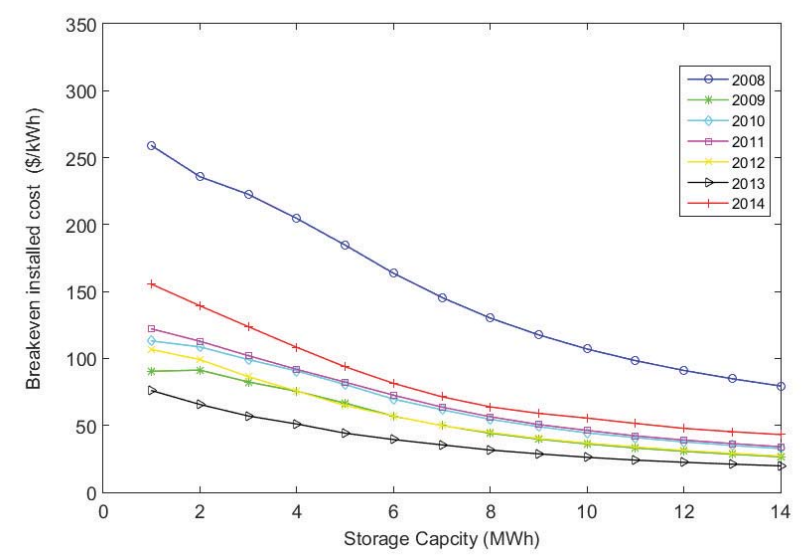

Fig. 10. Distribution of breakeven overnight installed cost for DeKalb, Georgia in the PJM RT-Market for an ESS vs. energy capacity (1-14 MWh) for each of the years studied. Assumed round trip efficiency is $70 \%$ and project lifetime is 20 years.

\section{CONClusions}

In this paper, we analyzed the potential arbitrage revenue of energy storage systems in PJM real-time markets from 2008 to 2014 for nine selected nodes. These nodes already have ESS in operation. Perfect foresight represents an upper limit to arbitrage revenue in the RTM and this paper provides achievable values using the DAM as a forecast for the RTM.

The potential revenue generated by a 1-MW system with various energy/power ratios was determined. The best opportunities for energy arbitrage through storage in these nine nodes were estimated for Hagerstown and Blairstown. The results presented in Figures 8-10 shown that the breakeven installed costs per kWh of energy capacity drop with increasing discharge duration.

For the 2008 equivalent LMP profile in Hagerstown, the installation of a 6-hour flow battery is profitable if the installed cost is under about $200 \$ / \mathrm{kWh}$. Other years and other locations require installed costs roughly half as large. Current ESS costs are not low enough for profitability, but recent ESS cost reductions are expected to continue and might bring the best nodes into profitability in the foreseeable future.

\section{REFERENCES}

[1] Eyer, J.; Corey, G. Energy Storage for the Electricity Grid: Benefits and Market Potential Assessment Guide; SAND2010-0815; Technical Report for Sandia National Laboratories: Livermore, CA, USA , 2010.

[2] Silverstein, K. New York City Aims To Cut Greenhouse Gas Emissions By Using Energy Storage, Forbes, Sep 22, 2017. Available online: https://www.forbes.com/sites/kensilverstein/2017/09/22/new-york-cityto-cut-greenhouse-gas-emissions-by-using-energystorage/\#3f7a6f7e9135 (accessed on 28 September 2017).

[3] Z. Bie, Y. Lin, G. Li and F. Li, "Battling the Extreme: A Study on the Power System Resilience," in Proceedings of the IEEE, vol. 105, no. 7, pp. 1253-1266, July 2017.

[4] K. P. Schneider, F. K. Tuffner, M. A. Elizondo, C.-C. Liu, Y. Xu, D. Ton, "Evaluating the feasibility to use microgrids as a resiliency resource", IEEE Trans. Smart Grid, vol. 8, no. 2, pp. 687-696, Mar. 2016.

[5] US Development of Energy (DOE), Global Energy Storage Database. Available online: http://www.energystorageexchange.org/projects (accessed on 20 September 2017).

[6] Salles, M.B.C.; Aziz, M.J.; Hogan, W.W. Potential Arbitrage Revenue of Energy Storage Systems in PJM during 2014. In Proceedings of the IEEE Power \& Energy Society General Meeting, Boston, MA, USA, 17-21 July 2016.

[7] William Steel, "Energy Storage Market Outlook 2017: State of Play", Renewable Energy World, February 2, 2017. Available online: http://www.renewableenergyworld.com/articles/print/volume-20/issue1/features/storage/energy-storage-market-outlook-2017-state-ofplay.html3f7a6f7e9135 (accessed on 30 September 2017).

[8] Stephen Lacey, "New Market Rules Destroyed the Economics of Storage in PJM. What Happened?", Energy Storage, GTM Research, June 21, 2017.

Available online: https://www.greentechmedia.com/articles/read/newmarket-rules-destroyed-the-economics-of-storage-in-pjm-whathappened\#gs.xqwSDcE (accessed on 30 September 2017).

[9] Andrew L. Ott, "Experience with PJM Market Operation, System Design and Implementation", IEEE Transactions on Power Systems, vol. 18, no. 2, May 2003.

[10] Salles, M. B., Huang, J., Aziz, M. J., \& Hogan, W. W. "Potential Arbitrage Revenue of Energy Storage Systems in PJM", Energies, v. 10, n. 8, p. $1100,2017$. 
[11] Sioshansi, R.; Denholm, P.; Jenkins, T.; Weiss, J. "Estimating the value of electricity storage in PJM: Arbitrage and some welfare effects." Energy Economics, v. 31, n. 2, p. 269-277, 2009.

[12] Luo, X.; Wang, J.; Dooner, M.; Clarke, J. "Overview of current development in electrical energy storage technologies and the application potential in power system operation." Applied Energy, v. 137, p. 511-536, 2015.

[13] Turker, B., Klein, S. A., Hammer, E. M., Lenz, B., \& Komsiyska, L. "Modeling a vanadium redox flow battery system for large scale applications." Energy conversion and management, v. 66, p. 26-32, 2013.

[14] J. Choi, W. K. Park and I. W. Lee, "Application of vanadium redox flow battery to grid connected microgrid energy management," 2016 IEEE International Conference on Renewable Energy Research and Applications (ICRERA), Birmingham, pp. 903-906, 2016.

[15] Denholm, P.; Ela, E.; Kirby, B.; Milliqan, M. "The Role of Energy Storage with Renewable Electricity Generation", Technical Report for NREL: Golden, CO, USA, 2010.

[16] Lazard. Lazard's Levelized Cost of Storage Analysis - Version 2.0. Available online: https://www.lazard.com/media/438042/lazardlevelized-cost-of-storage-v20.pdf (accessed on 1 September 2017).

[17] U.S. Energy Information Administration (EIA), spreadsheet AEO2014_financial.xls. Private communication, 2014. 